\title{
A new species of Pseudargyrochlamys Grichanov, 2006 from South Africa (Diptera: Dolichopodidae)
}

\author{
Новый виА Pseudargyrochlamys Grichanov, 2006 \\ (Diptera: Dolichopodidae) из Южной Африки
}

\author{
I.Ya. Grichanov \\ И.Я. Гричанов
}

\begin{abstract}
All-Russian Institute of Plant Protection, Podbelskiy roadway 3, St. Petersburg-Pushkin, 196608 Russia. E-mail: grichanov@mail.ru Всероссийский институт защиты растений, шоссе Подбельского, 3, Санкт-Петербург-Пушкин, 196608, Россия
\end{abstract}

KEY WORDS. Pseudargyrochlamys, new species, Afrotropics, southern Africa, key.

КЛЮЧЕВЫЕ СЛОВА. Pseudargyrochlamys, новый вид, Тропическая Африка, южная Африка, определитель.

ABSTRACT. The genus Pseudargyrochlamys Grichanov, 2006 is endemic to southern Africa. A new species, Pseudargyrochlamys londti sp.n. from the KwaZulu-Natal Province of the Republic of South Afri$\mathrm{ca}$ is described. It well differs from other species of the genus in the presence of brown spot on the male wing apex. A key to five known Pseudargyrochlamys species is compiled for the first time.

РЕЗЮМЕ. Род Pseudargyrochlamys Grichanov, 2006 - эндемик южной части Африки. Описан новый вид Pseudargyrochlamys londti sp.n. из провинции Квазулу-Натал Южно-Африканской Республики. Он хорошо отличается от других видов рода по коричневому пятну на вершине крыльев самца. Впервые составлен определитель пяти известных видов Pseudargyrochlamys.

The genus Pseudargyrochlamys Grichanov, 2006 has been created for four species of Paracleius Bigot, 1859 (now synonym to Pelastoneurus Loew, 1861) distributed along seashore of Eastern Cape and KwaZulu-Natal provinces of South Africa [Grichanov, 2004, 2006]. Grichanov [2006] compared his new genus with Argyrochlamys Lamb, 1922, known from Afrotropics and West Orient. Subsequently Naglis et al. [2013] have described Phoomyia Naglis et Grootaert from coastal Sri Lanka and Thailand, related the genus to Argyrochlamys and Pseudargyrochlamys, and compiled a key to the Argyrochlamys group of genera. Grichanov [2010] has reviewed the genus Argyrochlamys, and Grichanov [2016] has reported Phoomyia srilankensis Naglis et Brooks, 2013 in East India. Pseudargyrochlamys barracloughi (Grichanov, 2004) has been illustrated by Grichanov [2011] and Grichanov, Brooks [2017]. New records of $P$. barracloughi and P. jasoni (Grichanov, 2004) from South Africa and Mozambique have been published by Grichanov et al. [2011a, b].

In this paper a new peculiar species of Pseudargyrochlamys from South Africa is described, and an identification key to known species is firstly provided.

A new Pseudargyrochlamys species discovered is photographed with a ZEISS Discovery V-12 stereo microscope and an AxioCam MRc5 camera. Genitalia preparations have been photographed with a ZEISS Axiostar stereo microscope and an AxioCam ICc3 camera. Morphological terminology and abbreviations follow Cumming, Wood [2017] and Grichanov, Brooks [2017]. Body length is measured from the base of the antenna to the posterior tip of epandrium. Wing length is measured from the base to the wing apex. The types of new species are housed at the Natal Museum, Pietermaritzburg, KwaZulu-Natal, South Africa (NMSA).

Genus Pseudargyrochlamys Grichanov, 2006

Type species: Paracleius michaeli Grichanov, 2004, by original designation.

DIAGNOSIS. The genus is close to Argyrochlamys and Phoomyia, differing in head being distinctly higher than wide; female face narrow; female oviscapt with weak ventral lobes; hind basitarsus without strong dorsal seta; male hind tibia without bifurcate posteroapical projection; male hind basitarsus without comma-shaped posterobasal projection; male cercus usually large. Body non-metallic; frons black, grey or brownish pollinose, high, as high as face; male face very narrow, female face slightly wider, both almost parallel sided; thorax mainly yellow-orange with only black longitudinal stripe on mesonotum or mainly black with only metepimerons yellow-brown, weakly to densely pollinose; mesonotum without flattened region in front of scutellum; antennal stylus basodorsal, bare; 5 dorsocentrals in regular rows or

How to cite this article: Grichanov I.Ya. 2020. A new species of Pseudargyrochlamys Grichanov, 2006 from South Africa (Diptera: Dolichopodidae) // Russian Entomol. J. Vol.29. No.1. P.97-101. doi: 10.15298/ rusentj.29.1.14 
6 dorsocentrals, with $1^{\text {st }}$ and $5^{\text {th }}$ pairs small, and $5^{\text {th }}$ pair strongly offset medially; vein $M_{1+2}$ distinctly bent in distal part, reaching costa near the tip of wing; $R_{4+5}$ and $M_{1+2}$ nearly parallel at apex; $d m-m$ located at about basal third of wing, very short; hind femur bearing one true anterior subapical seta located far from distal apex; hind coxa with 1 strong external seta; hind basitarsus without setae above; hind basitarsus of male without comma-shaped posterobasal projection; abdomen mostly orange-yellow with black dorsolateral spots; male genitalia with proctiger brushes absent; female oviscapt hidden, with weak ventral lobes. Males differ from females in some male secondary sexual characters (MSSC). Females of close species are indistinguishable.

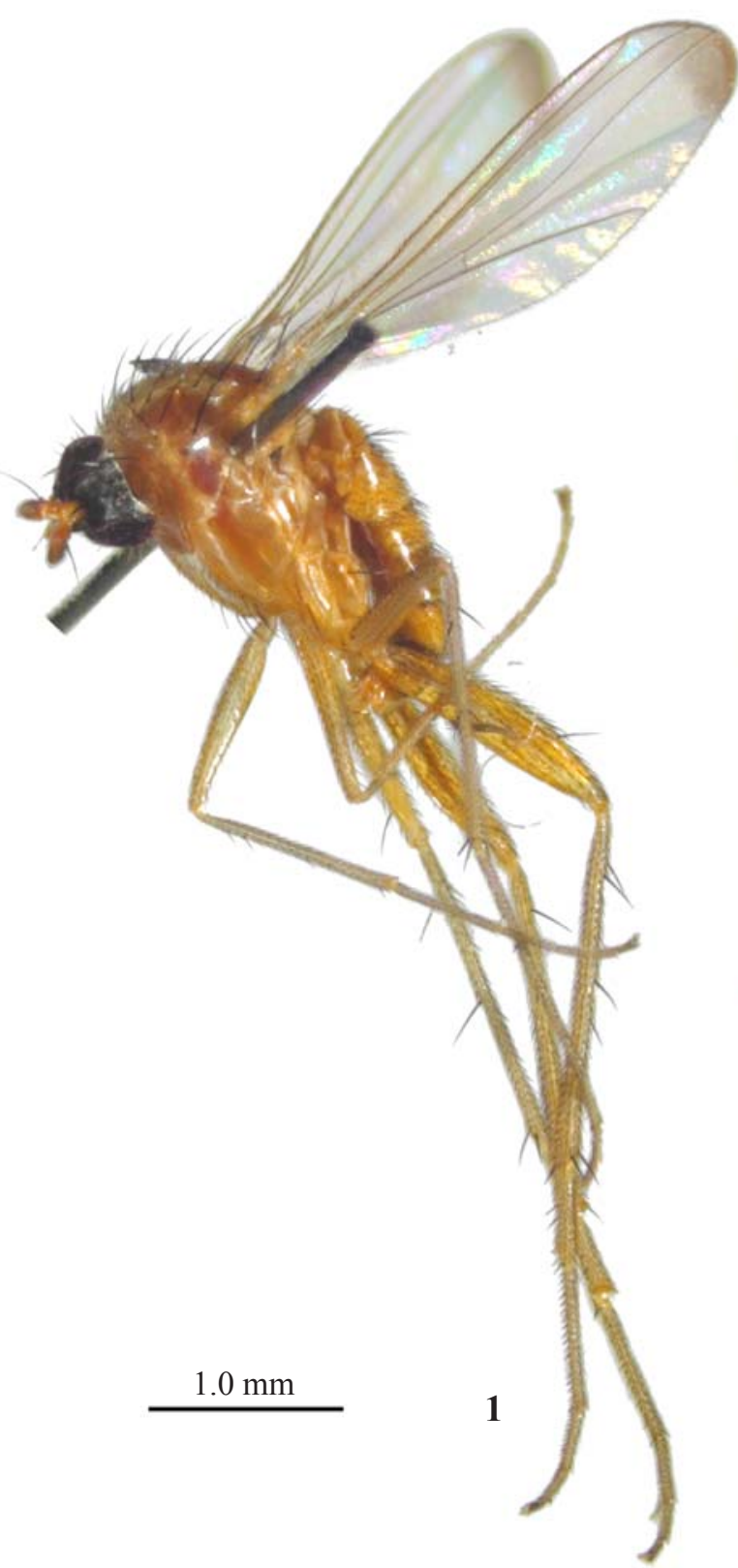

\section{Pseudargyrochlamys londti Grichanov, sp.n.}

Figs $1-11$.

MATERIAL. Holotype $\sigma^{7}$, South Africa: [KwaZulu-] Natal, Umhlali [River] mouth, collected on seashore, $\left[29.46^{\circ} \mathrm{S}, 31.28^{\circ} \mathrm{E}\right]$, 19.VI.1962, B. and P. Stuckenberg (NMSA); paratypes: $10^{7}$, South Africa: KwaZulu-Natal, Prince's Grant country Estate ca. $10 \mathrm{~km} \mathrm{E}$ Stanger, $29^{\circ} 21^{\prime} 33-$ S, $31^{\circ} 22^{\prime} 08-E, 30$ m, 18.IX.2000, J.G.H. Londt (NMSA); 1ㅇ, South Africa: [KwaZulu-] Natal, Umhlali, La Mercy, coastal bush, seashore, 24.I.1963, B. and P. Stuckenberg (NMSA).

DESCRIPTION. Male (Figs 1-5). Head (shrunken in all specimens). Frons as high as face, black, grey pollinose; face densely white pollinose; one long and strong vertical at the top of head, one shorter postvertical as a linear continuation

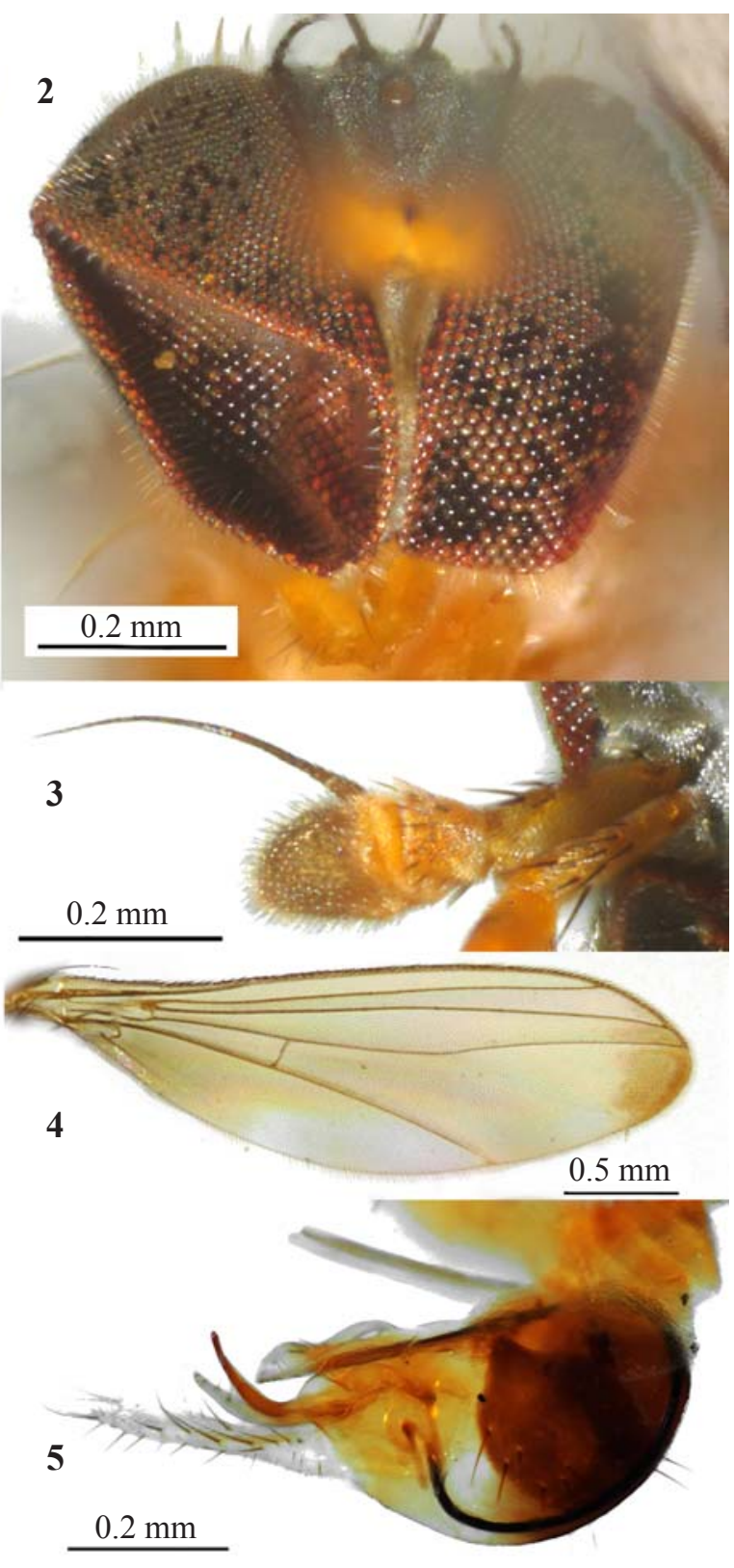

Figs 1-5. Pseudargyrochlamys londti Grichanov, sp.n., male: 1 - habitus, 2 - head, 3 - antenna, 4 - wing, 5 - hypopygium, lateral view.

Pис. 1-5. Pseudargyrochlamys londti Grichanov, sp.n., самец: 1 - внешний вид, 2 - голова, 3 - усик, 4 - крыло, 5 - гипопигий, сбоку. 
of postocular setal row, a pair of strong ocellar setae present; postocular setae white, few upper postoculars brown or black; eyes with short hairs; face glabrous, very narrow (MSSC), almost parallel-sided; clypeus not reaching lower margin of eyes; antenna positioned at middle of head, shorter than height of head; mostly orange-yellow; scape simple, with several black dorsal setulae; pedicel small, internally convex anteriad, with short distal setulae; postpedicel brown-black in distal half, with short hairs, ovate, 1.6 times longer than high at base (19/12; MSSC); arista-like stylus basodorsal, short, simple, black, with microscopic hairs; length ratio of scape to pedicel to postpedicel to stylus ( $1^{\text {st }}$ and $2^{\text {nd }}$ segments $)$, 16/9/19/4/33; palpus and proboscis small, yellow, with short hairs; palpus with 1 short yellow seta.
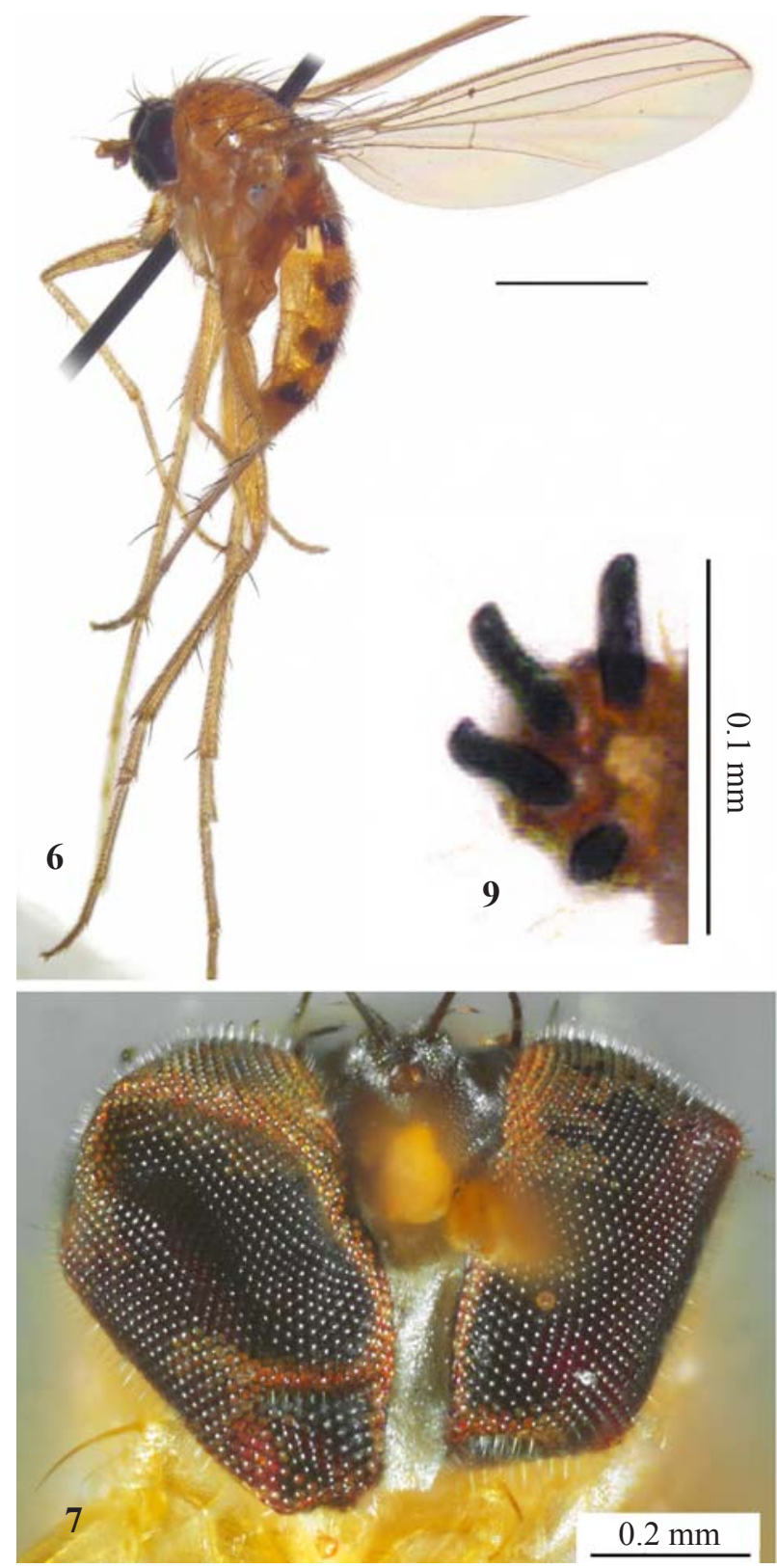

8

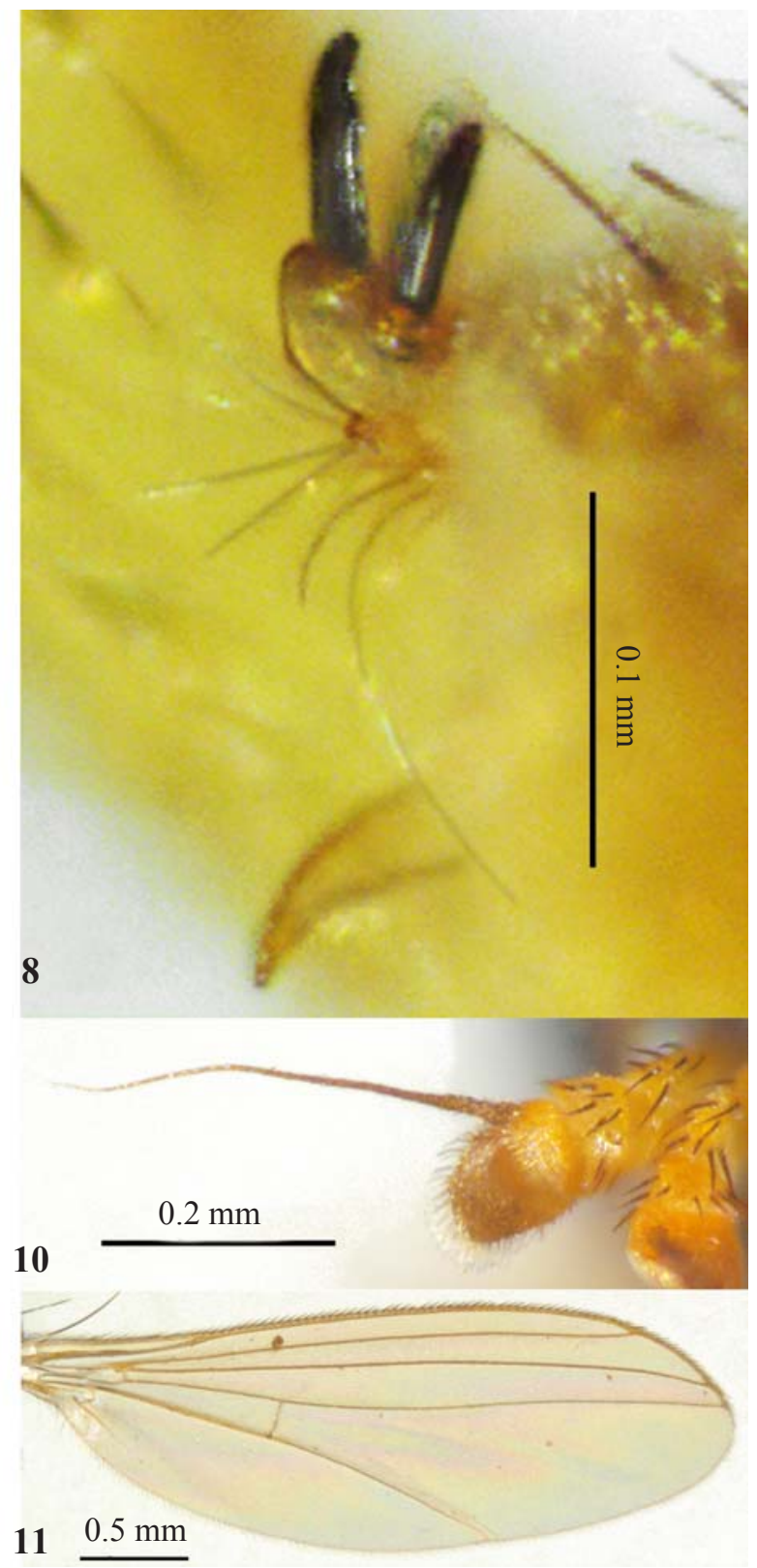

Figs 6-11. Pseudargyrochlamys londti Grichanov, sp.n., female: 6 - habitus, 7 - head, 8 - apex of oviscapt, lateral view, $9-$ hemitergites of oviscapt, dorsal view, 10 - antenna, 11 - wing.

Рис. 6-11. Pseudargyrochlamys londti Grichanov, sp.n., самка: 6 - внешний вид, 7 - голова, 8 - вершина яйцеклада, сбоку, 9 — гемитергиты яйцеклада, сверху, 10 - усик, 11 - крыло. 
apical setae; hind femur 5 times longer than high, with 1 anterodorsal seta at 7/10; hind tibia with 2 anterodorsal, 3-4 posterodorsal and 4 apical setae, without strong ventral setae; hind basitarsus with $2-3$ ventral setulae; $1^{\text {st }}-4^{\text {th }}$ tarsomeres each with several apicoventral setulae. Femur, tibia and tarsomere (from first to fifth) length ratio (in $\mathrm{mm}$ ): fore leg: 0.94/ 0.97/0.56/0.29/0.21/0.12/0.1, mid leg: 1.11/1.49/0.81/0.42/ 0.3/0.19/0.13, hind leg: 1.34/1.66/0.41/0.64/0.31/0.21/0.13.

Wing (Fig. 4) hyaline, with brown spot at apex (MSSC), veins yellow-brown; costa simple; $\mathrm{R}_{2+3}$ almost straight; ratio of part of costa between $\mathrm{R}_{2+3}$ and $\mathrm{R}_{4+5}$ to this between $\mathrm{R}_{4+5}$ and $\mathrm{M}_{1+2}, 34 / 12 ; \mathrm{R}_{4+5}$ slightly curved posteriad at apex; $\mathrm{M}_{1+2}$ having weak but distinct curvation at middle of distal part, then forming gentle arc, gradually converging to $\mathrm{R}_{4+5}$, almost parallel to $\mathrm{R}_{4+5}$ at wing apex, joining costa just before wing apex; crossvein $d m-m$ positioned just before middle of wing, straight, forming right angles with longitudinal veins; ratio of $\mathrm{dm}-\mathrm{m}$ to distal part of $M_{4}, 15 / 106$; posterior wing margin evenly convex; anal vein fold-like; anal lobe narrow; anal angle absent; lower calypter yellow, with black setae; halters orange-yellow.

Abdomen mostly orange-yellow, weakly pollinose; $2^{\text {nd }}-5^{\text {th }}$ tergites with small brown-black lateral spots at base; $7^{\text {th }}$ segment yellow, very short, $3 / 5$ length of epandrium; $8^{\text {th }}$ segment brown-black, with sparse fine dark cilia; epandrium brown-black in basal half, yellow in distal half, as long as $4^{\text {th }}$ $5^{\text {th }}$ tergites combined, semirounded, $1 / 3$ longer than high; hypandrium and phallus narrow, simple; distoventral epandrial lobe long and broad, slightly swollen in basal half, with 3 long setae at apex; postgonite as long as surstylus, brown, narrow, gently curved ventrally; surstylus yellow, with 2 lobes; ventral lobe short and broad, with 3 short subapical setae; dorsal lobe of surstylus narrow, strongly curved, with a few short setae; cercus yellow, long, narrow, 2/3 as long as epandrium, 4 times longer than wide at base, with simple white hairs and black setae along entire length.

Female (Figs 6-11). Similar to male except lacking MSSC; ratio of face height to face width under antenna to face width in middle, 34/11/7; postpedicel slightly longer than high at base (13/11); length ratio of scape to pedicel to postpedicel to stylus ( $1^{\text {st }}$ and $2^{\text {nd }}$ segments), 9/6/13/3/36; oviscapt with weak ventral lobes; each hemitergite with two thick spines (Figs 8-9).

Measurements (in mm). Body length 3.2-3.3, antenna length 0.6 , wing length $3.1-3.2$, wing width $0.9\left(\sigma^{T}\right)-1.1$ ( + ).

ETYMOLOGY. The species is named for one of the collectors, Dr. Jason Londt (NMSA).

DISTRIBUTION. South Africa.

DIAGNOSIS. The new species is a sister species to $P$. jasoni and P. michaeli (Grichanov, 2004), differing distictly in the presence of brown spot on wing apex. Hypopygium of $P$. londti sp.n. is quite similar to that in other species of the genus [Grichanov, 2004]. Nevertheless, the cercus length and length of setae on the distoventral epandrial lobe are somewhat different in males of all species.

\section{Key to KNOWN PSEUDARGYROCHLAMYS SPECIES}

1. Thorax mostly blackish grey; 5 dorsocentral setae; body length $2.2 \mathrm{~mm}$ (female) .......... P. umngazi (Grichanov)

- Thorax mostly yellow; 6 dorsocentral setae (males only)

................................................................... 2

2. Wing with brown spot at apex; body length $3.2-3.3 \mathrm{~mm}$

Wing hyaline P. londti sp.n.

3. Stylus 2 times longer than antennomeres combined, flagellate; body length $2.3-2.5 \mathrm{~mm}$

P. barracloughi (Grichanov)
- Stylus as long as antennomeres combined, simple ..... 4

4. Cercus half as long as epandrium; body length 1.7-2.6 $\mathrm{mm}$..................................... P. michaeli (Grichanov)

- Cercus nearly as long as epandrium; body length $2.3 \mathrm{~mm}$ P. jasoni (Grichanov)

\section{Conclusion}

Pseudargyrochlamys species are confined to coastal band of southern Africa between East London (South Africa) and Maputo (Mozambique). The described species inhabit coastal bush and dunes, seashore, forest and open woodland areas near bays and estuaries (Grichanov, 2004, and this paper). Species of the related Argyrochlamys and Phoomyia populate similar sandy habitats [Grichanov, 2010; Naglis et al., 2013], which caused apparently such adaptation as densely grey pruinose, non-metallic body with the domination of yellow-orange or blackish brown or grey colour. The great majority of other members of the subfamily Dolichopodinae have mainly metallic green or violet shine on thorax and abdomen.

Pseudargyrochlamys londti sp. $\mathbf{n}$. is found only in the KwaZulu-Natal Province, in three habitats at the Umhlali River lower reach, being probably endemic of the territory. As a result of this study, the genus Pseudargyrochlamys includes five species known from South Africa, two from the Eastern Cape and four species from the KwaZulu-Natal province.

Acknowledgments. The author is sincerely grateful to Mike Mostovsky (at present the Steinhardt Museum of Natural History, Tel Aviv, Israel) for providing the specimens studied in this research. The work was funded by RFBR and NSFC according to the research project No. 20-54-53005. The comparative analysis of morphological characters and the preparation of illustrations were performed within the Program for Basic Scientific Research of the Government of the Russian Federation, project No. 0665-2020-0014. Two anonymous reviewers kindly commented on earlier drafts of the manuscript.

\section{References}

Cumming J.M., Wood D.M. 2017. 3. Adult morphology and terminology // A.H. Kirk-Spriggs, B.J. Sinclair (eds.). Manual of Afrotropical Diptera. Vol.1. Nematocerous Diptera and lower Brachycera. Suricata 4. Pretoria: SANBI Graphics and Editing. P.89-134.

Grichanov I.Ya. 2004. Review of Afrotropical Dolichopodinae (Diptera: Dolichopodidae) // Plant Protection News Suppl. St. Petersburg: VIZR. P.1-244.

Grichanov I.Ya. 2006. New genera and new combinations for afrotropical Dolichopodinae (Dolichopodidae, Diptera) // International Journal of Dipterological Research. Vol.17. No.1. P.23-34.

Grichanov I.Ya. 2010. Species of the genus Argyrochlamys Lamb, 1922 (Diptera: Dolichopodidae) // Caucasian Entomological Bulletin. Vol.6. No.1. P.113-115.

Grichanov I.Ya. 2011. An illustrated synopsis and keys to Afrotropical genera of the epifamily Dolichopodoidae (Diptera: Empidoidea) // Priamus Serial Publication of the Centre for Entomological Studies Ankara Supplement. Vol.24. P.1-99.

Grichanov I.Ya. 2016. Two new species of Campsicnemus Haliday, 1851 from India with notes on some Oriental Dolichopodidae (Diptera) // Halteres. Vol.7. P.35-42. 
Grichanov I.Ya., Brooks S.E. 2017. 56. Dolichopodidae (longlegged dance flies) // A.H. Kirk-Spriggs, B.J. Sinclair (eds.). Manual of Afrotropical Diptera. Vol.2. Nematocerous Diptera and lower Brachycera. Suricata 5. Pretoria: SANBI Graphics and Editing. P. 1265-1320

Grichanov I.Ya., Mostovski M.B., Muller B. 2011a. New records of Afrotropical Dolichopodidae (Diptera) from the collection of Natal Museum (1) // International Journal of Dipterological
Research. Vol.22. No.1. P.3-9.

Grichanov I.Ya., Mostovski M.B., Muller B. 2011b. New records of Afrotropical Dolichopodidae (Diptera) from the collection of Natal Museum (2) // International Journal of Dipterological Research. Vol.22. No.2. P.81-98.

Naglis S., Grootaert P., Brooks S.E. 2013. Phoomyia, a new genus of

Dolichopodinae from the Oriental Region (Diptera: Dolichopodidae) // Zootaxa. Vol.3666. No.1. P.93-99. 